\title{
Nasal obstruction as a risk factor for sleep apnoea syndrome
}

\author{
F. Lofaso*, A. Coste**, M.P. d'Ortho**, F. Zerah-Lancner**, C. Delclaux**, \\ F. Goldenberg**, A. Harf**
}

Nasal obstruction as a risk factor for sleep apnoea syndrome. F. Lofaso, A. Coste, MP. d'Ortho; F. Zerah-Lancner, C. Delclaux, F. Goldenberg, A. Harf. (C) ERS Journals Ltd 2000. ABSTRACT: Nasal obstruction has frequently been mentioned as a possible risk factor in obstructive sleep apnoea syndrome (OSAS).

Over a 2-yr period, 541 unselected consecutive snorers referred for suspected breathing disorders during sleep were included to undergo posterior rhinomanometry. In addition cephalometric landmarks and body mass index (BMI) were obtained. Polysomnography was used to determine the number of abnormal respiratory events that occurred during sleep. OSAS was defined as 15 episodes, or more, of apnoea or hypopnoea per hour of sleep (AHI).

Of the 541 consecutive snorers 528 underwent nasal resistance measurement by posterior rhinomanometry (failure rate: $2.4 \%$ ). Patients with OSAS (259 patients) had higher nasal resistance than patients without OSAS $\left(2.6 \pm 1.6 \mathrm{hPa} \cdot \mathrm{L} \cdot \mathrm{s}^{-1}\right.$ versus 2.2 $\pm 1.0 \mathrm{hPa} \cdot \mathrm{L} \cdot \mathrm{s}^{-1}$, respectively, $\mathrm{p}<\mathbf{0 . 0 0 5}$ ).

A stepwise multiple regression analysis showed that BMI, male sex, nasal resistance, and cephalometric parameters were contributing factors to the AHI. The $\mathbf{r}^{2}$ value of the multiple regression analysis was 0.183 . Nasal resistance contributed $2.3 \%$ of the variance $(\mathbf{p}<\mathbf{0 . 0 0 0 1})$, whereas mandibular plane-hyoid distance, BMI, male sex and age contributed $6.2 \%, 4.6 \%, 3 \%$ and $1.3 \%$ of the variance, respectively.

To conclude, daytime nasal obstruction is an independent risk factor for OSAS. Eur Respir J 2000; 16: 639-643.
*Service de Physiologie-Explorations Fonctionnelles, Hôpital Raymond Poincaré, Garches, France. **Service de Physiologie-Explorations Fonctionnelles, Institut National de la Santé et de la Recherche Médicale, Hôpital Henri Mondor, France.

Correspondence: F. Lofaso

Service de Physiologie-Explorations Fonctionnelles

Hôpital Raymond Poincaré

92380 Garches

France

Fax: 33147107943

Keywords: cephalometric roentgenogram obesity

Received: January 22000

Accepted after revision May 312000
Obstructive sleep apnoea syndrome (OSAS) occurs because of recurrent occlusion of the upper airway during sleep. Upper airway size is determined by soft-tissue and skeletal factors that are also the major determinants of upper airway patency during sleep. In obese patients, increased adipose tissue in the neck may predispose to airway narrowing. Accordingly, several studies have evaluated the effects of obesity and of craniomandibular abnormalities on the prevalence of OSAS. Results demonstrated that both factors predicted the presence or absence of OSAS [1-3].

Because increasing nasal resistance results in an increase in negative oropharyngeal pressure during inspiration, nasal obstruction may also predispose to upper airway collapse. Nasal obstruction has frequently been mentioned as a possible factor in OSAS [4-9]. Correction of nasal obstruction has been reported to be an effective treatment of OSAS in patients with nasal obstruction but no craniomandibular abnormalities [10]. These data suggest that nasal obstruction may be a risk factor for OSAS and may deserve attention during the investigation of snorers referred for suspected OSAS. However, previous studies using objective nasal resistance measurement in snorers did not find nasal obstruction to be a risk factor for OSAS [11, 12]. Similarly, Young et al. [13] failed to demonstrate any correlation between nasal resistance and sleep-disordered breathing in a sample of the general population.
In this 2-yr prospective study, nasal resistance in 541 unselected consecutive snorers referred for suspected sleep disorders was measured. The effect of nasal resistance on the risk of obstructive sleep apnoea syndrome was then compared to that of established anthropometric risk factors including obesity, sex, and cephalometric landmarks.

\section{Methods}

\section{Patient selection}

Five hundred and forty-one consecutive patients (457 males and 84 females) who attended the sleep clinic for snoring and varying degrees of daytime somnolence were included in the study.

Exclusion criteria were a history of evaluation or treatment for sleep apnoea and a history of surgery on the upper airway.

\section{Sleep studies}

Overnight sleep studies were performed in all patients and comprised of a full polysomnography including electroencephalography (C4-A1, C3-A2), electrooculography, chin electromyography, nasal airflow using a nasal prong device (Taema, Antony, France) connected to a pressure transducer (Validyne MP $45 \pm 14 \mathrm{cmH}_{2} \mathrm{O}$, Northridge, CA, 
USA) and oral airflow using thermistor, ribcage and abdominal movements monitored with piezoelectric strain gauges, and arterial oxygen saturation $\left(\mathrm{Sa}_{\mathrm{a}} \mathrm{O}_{2}\right)$ monitored via a finger probe (Nellcor N200, Nellcor Inc., Hayward, USA).

Sleep staging was performed using standard criteria [14]. Apnoea during objectively measured sleep was defined based on widely used clinical criteria: complete cessation of airflow lasting $10 \mathrm{~s}$ or more. Hypopnoea was defined as either at least a $50 \%$ decrease in nasal canula signal lasting $10 \mathrm{~s}$ or more without oral flow detection or decrease in nasal canola signal associated with a 3\% drop in $\mathrm{Sa}, \mathrm{O}_{2}$ and/or terminated with an arousal. The average number of apnoeas and hypopnoeas per hour of sleep (AHI) was calculated from the sum of sleep-disordered events. For the categorical analysis, an AHI cut-off of 15 per $h$ of sleep was used to define the presence of obstructive sleep apnoea syndrome.

\section{Pulmonary function}

Spirometry measurements and flow-volume curves were obtained using a spirometer (MedGraphics, PF/Dx 1085D, St. Paul, MN, USA). The highest values of three technically satisfactory forced expirations were used. All values were expressed as percentages of predicted values [15].

Arterial blood was drawn from the radial artery with the patient awake and semi-recumbent. The blood sample was analysed for oxygen tension in arterial blood $\left(\mathrm{Pa}_{\mathrm{a}} \mathrm{O}_{2}\right)$ (Blood gas analyser Radiometer ABL 520, Copenhagen, Denmark).

\section{Cephalometric analysis}

Lateral cephalometric roentgenograms were obtained using the technique described by RiLEY et al. [16]. The following angles (in degrees) and dimensions (in millimetres) were measured SNA, angle-measurement from the sella (S) to the nasion $(\mathrm{N})$ to point A (subspinale); $\mathrm{SNB}$, angle-measurement from the sella (S) to the nasion (N) to point B (supramentale); MP-H, distance between the mandibular plane (MP) to the hyoid bone $(\mathrm{H})$; PAS, posterior airway space, defined as the space located behind the base of the tongue and limited by soft tissues; and PNS-P, distance between the posterior nasal spine and the tip of the soft palate.

\section{Rhinomanometry}

Recordings of nasal resistance to airflow were carried out using a posterior rhinomanometry method recently described [17]. Briefly, to facilitate oropharyngeal pressure evaluation, rather than a face mask, the subjects wore a nasal mask (Respironics vinyl masks, Nantes, France) and a sealed mouthpiece. This mask had a soft plastic rim that sealed tightly without deforming the nose and the mouthpiece was modified by cutting off the lower part intended to be placed between the teeth and lower lip. This condition allowed protrusion of the tongue out of the mouth, thus facilitating oropharyngeal pressure measurement.
Flow measurements were carried out using a Fleisch \#l pneumotachograph (MSR, Rungis, France). The pneumotachograph was connected to a pressure transducer (Validyne MP $45 \pm 2 \mathrm{hPa}$, Northridge, CA, USA).

Transnasal pressure was determined by measuring the difference between the pressure at the level of the sealed mouthpiece and the pressure in the nasal mask with a differential pressure transducer (Validyne MP $45 \pm 14 \mathrm{hPa}$, Northridge, CA).

Pressure and flow signals were recorded simultaneously at a rate of $32 \mathrm{~Hz}$ on the hard disk of a microcomputer, using the Acknowledge software and device (Biopac Systems Inc., Santa Barbara, CA, USA). With this software, the pressure-time and flow-time curves, together with the pressure-flow curve, can be displayed in real time, allowing visual feedback to the patients from the trace on a monitor. Data were processed immediately after each 30 -s recording to compute resistance as the pressure-flow ratio at a transnasal pressure of $1 \mathrm{hPa}$ [18].

The measurements were performed while the patient was breathing through each nostril separately (unilateral nasal resistance) and through both nostrils at the same time (nasal resistance). When basal bilateral nasal resistance was $\geq 2.5 \mathrm{hPa} \cdot \mathrm{L} \cdot \mathrm{s}^{-1}$, or when basal unilateral nasal resistance for one nostril was $\geq 6 \mathrm{hPa} \cdot \mathrm{L} \cdot \mathrm{s}^{-1}$, the measurements were repeated after administration of a topical nasal vasoconstrictor (postdecongestant nasal resistance).

\section{Statistical analysis}

Data were expressed as mean \pm SD. Comparison of patients with and without OSAS according to the apnoea-hypopnoea index (AHI) was carried out using the unpaired t-test. A chi-squared test to compare the distribution of males and females in both groups was also used.

Regression analysis was performed to determine the relative contributions to AHI variability of age, sex BMI, smoking history (pack-years), pulmonary function tests, craniofacial abnormalities and nasal resistances including basal nasal resistance, postdecongestant nasal resistance, and the highest unilateral nasal resistance. Univariate analysis was used to evaluate the independent contributions of each of the above variables. A full model stepwise multiple linear regression analysis was then performed to determine the influence of each variable.

For all comparisons, p-values $<0.05$ were considered significant.

\section{Results}

The study included 541 consecutive patients. No neuromuscular patients were enlisted. Forty-five patients presented a Forced expiratory volume in one second (FEV1)/ Vital capacity (VC) below $80 \%$ of the predicted value. Of the 272 nonOSAS patients with an apnoea-hypopnoea index (AHI) of less than 15 per $h$, three $(1.1 \%)$ failed rhinomanometry, versus $10(3.7 \%)$ of the 269 OSAS patients with an AHI of 15 per h or more. These ten patients had a similar mean AHI than the 259 OSAS successfully investigated patients $(42 \pm 15$ versus $37 \pm 19)$ but had an older mean age $(70 \pm 19$ yrs versus $55 \pm 15$ yrs $)$. 
Table 1. - Anthropometric parameters, lung function, nasal resistances, cyhalometric values and apnoeahypopnoea index in the two groups of patients

\begin{tabular}{|c|c|c|c|}
\hline & $\mathrm{AHI}<15$ & $\mathrm{AHI} \geq 15$ & $\begin{array}{l}\text { t-test } \\
\text { or } \chi^{2}\end{array}$ \\
\hline $\mathrm{n}$ & 269 & 259 & \\
\hline AHI $\mathrm{n} / \mathrm{h}$ & $6.4 \pm 4.1$ & $37.5 \pm 23.3$ & \\
\hline Sex & $194 \mathrm{M}$ & $251 \mathrm{M}$ & $\mathrm{p}<0.0001$ \\
\hline Age, yr & $51 \pm 15$ & $55 \pm 15$ & $\mathrm{p}<0.0001$ \\
\hline $\mathrm{BMI} \mathrm{kg} \cdot \mathrm{M}^{-2}$ & $27.9 \pm 5.1$ & $29.9 \pm 5.9$ & $\mathrm{p}<0.0001$ \\
\hline Smoking history pack yr & $12.5 \pm 16.7$ & $18.4 \pm 22.0$ & $\mathrm{p}<0.0001$ \\
\hline$P a, O_{2} \mathrm{kPa}$ & $86 \pm 12$ & $82 \pm 12$ & $\mathrm{p} \geq 0.0001$ \\
\hline VC \% pred & $102 \pm 15$ & $98 \pm 14$ & $\mathrm{p}<0.0001$ \\
\hline FEV1/VC \% pred & $95 \pm 11$ & $94 \pm 12$ & NS \\
\hline $\begin{array}{l}\text { Basal nasal resistance } \\
\mathrm{hPa} \cdot \mathrm{L} \cdot \mathrm{s}^{-1}\end{array}$ & $2.2 \pm 1.0$ & $2.6 \pm 1.6$ & $\mathrm{p}<0.005$ \\
\hline $\begin{array}{l}\text { Highest unilateral nasal } \\
\text { resistance } \mathrm{hPa} \cdot \mathrm{L} \cdot \mathrm{s}^{-1}\end{array}$ & $7.5 \pm 9.2$ & $9.2 \pm 10.9$ & NS \\
\hline SNA angle, degrees & $81.9 \pm 4.7$ & $81.6 \pm 4.2$ & NS \\
\hline SNB angle, degrees & $79.3 \pm 4.4$ & $78.5 \pm 4.0$ & $\mathrm{p}<0.02$ \\
\hline PNS-p, mm & $40.1 \pm 6.0$ & $42 \pm 6.0$ & $\mathrm{p}<0.0001$ \\
\hline PAS, mm & $11.9 \pm 3.9$ & $11.9 \pm 4.3$ & NS \\
\hline MP-H, mm & $18.3 \pm 5.7$ & $20.5 \pm 6.7$ & $\mathrm{p}<0.0001$ \\
\hline
\end{tabular}

AHI: apnoea-hypopnoea index; BMI: body mass index; VC: vital capacity; FEV1: forced vital capacity in one second; SNA: angle measurement from the sella $(\mathrm{S})$ to the nasion $(\mathrm{N})$ to point A (subspinal); SNB: angle measurement from the sella to the nasion to point B (supramental); PNS-P: distance from the posterior nasal spine to the tip of the soft palate; PAS: posterior airway space; MP-H: distance from the mandibular plane (MP) to the hyoid bone $(\mathrm{H}) . \mathrm{Pa}_{\mathrm{a}} \mathrm{O}_{2}$ : arterial oxygen pressure.

Anthropometric, pulmonary function, nasal resistance, cephalometric and AHI data are shown in table 1. Age, sex ratio $(\mathrm{M} / \mathrm{F})$, and $\mathrm{BMI}$ were significantly higher in the OSAS than in the nonOSAS group. Comparisons of cephalometric measurements showed that SNA and PAS were similar in the OSAS and nonOSAS patients, whereas SNB was lower and PNS-P and MP-H were higher in the OSAS patients. The sex ratio $(\mathrm{M} / \mathrm{F})$ was significantly higher in the OSAS group (table 1).

Nasal resistance was significantly higher in the OSAS group than in the nonOSAS group. However, the highest unilateral nasal resistance was not significantly different between the two groups (table 1).

The results of the univariate regression analysis on AHI of the anthropometric variables, pulmonary function variables and nasal resistances are shown in table 2. Age, BMI, male sex, smoking history, nasal resistance, cephalometric abnormalities, $P \mathrm{a}, \mathrm{O}_{2}$ and VC were significantly correlated with OSAS severity. In contrast, no correlation was found between the highest basal unilateral nasal resistance or the FEV1/VC and the AHI. Postdecongestant nasal resistance, assessed in 248 patients, showed a weaker correlation with AHI than basal nasal resistance (table 2).

Distribution of nasal resistance in both groups is shown in histogram form in figure 1. Resistance levels of less than $<3 \mathrm{hPa} \cdot \mathrm{L} \cdot \mathrm{s}^{-1}$ were more prevalent in nonOSAS than in OSAS patients, whereas the opposite occurred for resistance levels $>3 \mathrm{hPa} \cdot \mathrm{L} \cdot \mathrm{s}^{-1}$. In fact, patients who presented a nasal resistance $\geq 3 \mathrm{hPa} \cdot \mathrm{L} \cdot \mathrm{s}^{-1}$ showed a significantly greater risk of having OSAS (odds ratio, 2.2).
Table 2. - Univariate regression analysis on $\mathrm{AHI}$ of anthropometric variables, smoking history, pulmonary function and nasal resistances

\begin{tabular}{|c|c|c|c|c|}
\hline & $\begin{array}{l}\text { Coef- } \\
\text { ficient }\end{array}$ & $\begin{array}{l}95 \% \\
\text { confidence } \\
\text { interval }\end{array}$ & $r^{2}$ & p-value \\
\hline Age, yr & 0.32 & $0.14-0.50$ & 0.023 & $<0.001$ \\
\hline $\mathrm{BMI} \mathrm{kg} \cdot \mathrm{M}^{2}$ & 0.98 & $0.65-1.31$ & 0.057 & $<0.0001$ \\
\hline $\operatorname{Sex}^{+}$ & 10.50 & $5.50-15.50$ & 0.032 & $<0.0001$ \\
\hline MP-H,mm & 0.97 & $0.67-1.27$ & 0.071 & $<0.0001$ \\
\hline PNS-P, mm & 0.79 & $0.46-1.12$ & 0.045 & 0.0001 \\
\hline SNB, degrees & -0.48 & $-0.96-0.00$ & 0.008 & $<0.05$ \\
\hline $\begin{array}{l}\text { Smoking history } \\
\text { pack yr }\end{array}$ & 0.25 & $0.14-0.36$ & 0.045 & $<0.0001$ \\
\hline$P \mathrm{a}, \mathrm{O}_{2} \mathrm{kPa}$ & -0.42 & $-0.58--0.26$ & 0.045 & $<0.0001$ \\
\hline VC \% pred & -0.26 & $-0.39--0.13$ & 0.026 & $<0.0002$ \\
\hline $\mathrm{FEV} 1 / \mathrm{VC} \%$ pred & 0.00 & $-0.17-0.17$ & 0.00001 & 0.99 \\
\hline $\begin{array}{l}\text { Bilateral nasal } \\
\text { resistance } \mathrm{hPa} \cdot \mathrm{L} \cdot \mathrm{s}^{-1}\end{array}$ & 2.91 & $1.46-4.36$ & 0.029 & $<0.0001$ \\
\hline $\begin{array}{l}\text { Postdecongestant } \\
\text { nasal resistance } \\
\mathrm{hPa} \cdot \mathrm{L} \cdot \mathrm{s}^{-1}\end{array}$ & 4.77 & $0.16-9.38$ & 0.017 & $<0.05$ \\
\hline $\begin{array}{l}\text { Highest unilateral } \\
\text { nasal resistance } \\
\mathrm{hPa} \cdot \mathrm{L} \cdot \mathrm{s}^{-1}\end{array}$ & 0.10 & $-0.10-0.30$ & 0.002 & 0.28 \\
\hline
\end{tabular}

Regression analyses were performed in 528 patients, except for that of postdecongestant nasal resistance, which was done in 248 patients. ${ }^{+}$: male $=1$, female $=0$ for the regression analysis. BMI: body mass index; MP-H: distance from the mandibular plane (MP) to the hyoid bone (H); PNS-P: distance from the posterior nasal spine to the tip of the soft palate; SNB: angle measurement from the sella to the nasion to point $\mathrm{B}$ (supramental); $\mathrm{Pa}_{2} \mathrm{O}_{2}$; arterial oxygen pressure; $\mathrm{VC}$ : vital capacity: FEV1: forced vital capacity in one second.

The results of the stepwise multiple regression analysis on AHI of age, anthropometric, smoking, pulmonary function and nasal resistance variables are shown in table 3. Nasal resistance, age, BMI, male sex, and cephalometric parameters were contributing factors to OSAS. The $\mathrm{r}^{2}$-value of the stepwise multiple regression analysis was 0.183 . MP-H contributed $6.2 \%$ of the AHI variance, BMI 4.6\%, male sex 3.0\%, nasal resistance 2.3\%, age $1.3 \%$ and SNB $0.9 \%$

\section{Discussion}

There is clinical evidence supporting a role for acute or chronic nasal obstruction in OSAS. MCNICHOLAS et al. [8] and LAVIE et al. [6] demonstrated that nasal obstruction due to allergic rhinitis was associated with both sleep fragmentation and OSAS. The OSAS appeared to be reversible during remissions of the allergic symptoms. Similarly, ZwILLICH et al. [5] and LAVIE et al. [7] compared apnoea during sleep experienced by normal subjects with and without experimentally-induced nasal obstruction and found that nasal obstruction induced episodes of apnoea and episodes of arousal from sleep. Chronic abnormalities such as septal deviation and nasal valve obstruction have also been reported to result in sleep disturbance and OSAS that diminished significantly after relief of the nasal obstruction [19]. SÉRIĖs et al. [10] have demonstrated that surgical correction of nasal obstruction is an effective treatment of mild OSAS in patients with nasal 


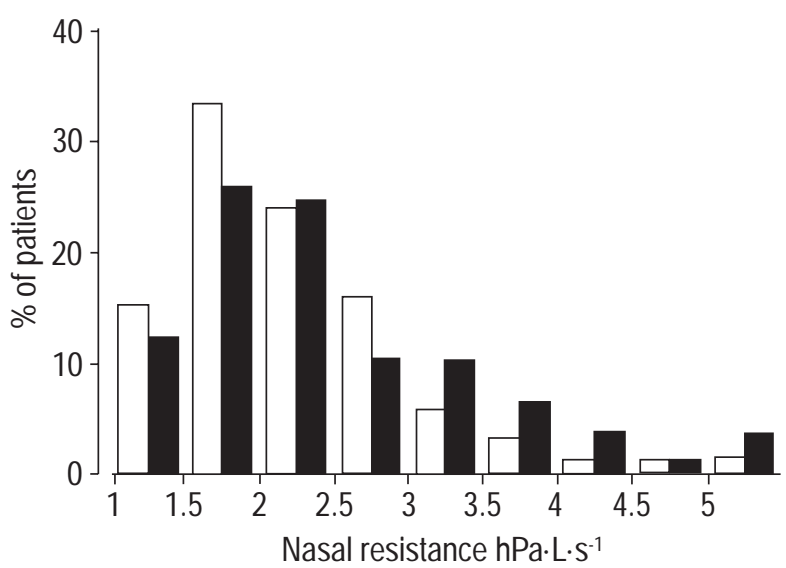

Fig. 1. - Histogram showing the distribution of basal bilateral nasal resistance in the obstructive sleep apnoea syndrome (OSAS) ( $\square$ ) and nonOSAS $(\square)$ groups. Almost all levels of basal bilateral nasal resistance lower than $3 \mathrm{hPa} \cdot \mathrm{L} \cdot \mathrm{s}^{-1}$ were more prevalent in the nonOSAS than in the OSAS group. Conversely, almost all levels of basal bilateral nasal resistance greater than $3 \mathrm{hPa} \cdot \mathrm{L} \cdot \mathrm{s}^{-1}$ were more prevalent in the OSAS than in the nonOSAS group.

obstruction but no cephalometric abnormalities. Taken as a whole, these data suggest that the list of potential risk factors for OSAS includes not only BMI, male sex, and cephalometric abnormalities, but also nasal obstruction.

This study differs from previous attempts to evaluate nasal resistance in OSAS [11-13, 20, 21] regarding a number of methodological characteristics, including the technique used for rhinomanometry and the characteristics of the study population.

Of the three studies that used anterior rhinomanometry, two failed to find any differences between OSAS patients and controls. Anterior rhinomanometry has the important advantage of being easy to perform. However, it requires that the patient breathe in a nonnatural way during the investigation, and it involves use of Ohm's law for parallel resistors, which is reliable only for the decongested note [18] for total nasal resistance calculation. ATKINS et al. [12] reported that anterior rhinomanometry failed to demonstrate any differences in nasal resistance between

Table 3. - Stepwise multiple regression analysis of apnoea-hypopnoea index (AHI) on age, anthropometric variables, smoking, pulmonary function and nasal obstruction variables. Only significant data are presented

\begin{tabular}{lcccc}
\hline & Coefficient & $\begin{array}{c}95 \% \\
\text { Confidence } \\
\text { interval }\end{array}$ & $\mathrm{r}^{2}$ & p-value \\
\hline Sex M $=1$ & 6.5 & & 0.030 & $<0.0001$ \\
MP-H, mm & 0.46 & $0.14-0.78$ & 0.062 & $<0.0001$ \\
BMI kg.M & 0.76 & $0.38-1.14$ & 0.046 & $<0.0001$ \\
Nasal resistance & & & & \\
hPa $\cdot \mathrm{L} \cdot \mathrm{s}^{-1}$ & 2.26 & $0.82-3.70$ & 0.023 & $<0.0001$ \\
Age yrs & 0.17 & $-0.02-0.37$ & 0.013 & $<0.0001$ \\
SNB, degrees & -0.55 & $-1.01--0.09$ & 0.009 & $<0.0001$ \\
\hline
\end{tabular}

This stepwise multiple regression analysis tested the variables that were significantly correlated to AHI in the univariate regression analysis of data from the 528 patients. MP-H: distance from the mandibular (MP) plane to the hyoid bone $(\mathrm{H})$; BMI: body mass index; SNB: angle measurement from the sella to the nasion to point $\mathrm{B}$ (supramental).
OSAS and nonOSAS patients. However, their sample size was limited to 71 OSAS patients and 70 nonOSAS snorers. Young et al. [13] studied a larger group, of 911 subjects, but similarly failed to demonstrate a correlation between OSAS severity and objective nasal resistance as measured by anterior rhinomanometry. A possible explanation for this negative result is that the study was performed in a population-based sample where OSAS-as defined by an AHI of 15 per h or more was not severe and concerned only $9 \%$ of males and $4 \%$ of females [22]. BLAKELY and MAHOWALD [20] also used anterior rhinomanometry in 90 subjects. Although they failed to demonstrate a correlation between nasal resistance and apnoea severity, they found that nasal resistance was higher in OSAS patients than in the control group. This positive result observed despite the small number of subjects tested may be ascribable to the sharp contrast between the two study groups: the cases of OSAS were severe (with AHIs of up to 120 per h), and the control group was composed of normal subjects rather than of snorers without OSAS.

Using postnasal rhinomanometry in 683 patients, MILJETEIG et al. [11] found no statistically significant relationships between nasal resistance and either snoring or OSAS. These findings are different from those in the present study. However, direct comparison of the two studies is difficult for several reasons. 1) Miljeteig et al. [11] compared only the snoring index and AHI between patients with normal and abnormal nasal resistance, without performing regression analysis. 2) The method for nasal resistance measurement was not the same in the two studies. Miljeteig et al. [11] used postnasal rhinomanometry, in which pharynegeal pressure was recorded through a lidocaine gel-lubricated catheter inserted $8 \mathrm{~cm}$ along the floor of the wider nasal cavity. This catheter reduced the calibre of the nasal pathway and may have interfered with the normal physiology of the nasal mucosa, inducing nasal congestion. Posterior rhinomanometry, a method that does not modify the nasal pathway provided the mask does not distort the anterior nares was used. To avoid such distortion, new-generation nasal masks designed for constant positive airway pressure (CPAP) therapy in OSAS were used. These masks do not distort the nose and are comfortable to wear. The other key point in posterior rhinomanometry is to keep the tongue away from the palate so as to allow free communication between the oropharynx and the oral cavity and reliable measurement of transnasal pressure by means of an oral tube. Insufficient upper airway control is frequent and has led to posterior rhinomanometry failure rates of at least $15 \%$ [18]. In our study, the posterior rhinomanometry variant described previously was used [17]. In this variant, protrusion of the tongue out of the mouth is used to facilitate pressure transmission between the nasopharynx and the mouth. Failure rates were as low as $1.1 \%$ and $3.7 \%$ in nonOSAS and OSAS patients, respectively, with this new method, which therefore, appears to be especially well-suited to nasal resistance measurement in snorers.

DESFONDS et al. [23] also used a posterior rhinomanometry method to separate OSAS and nonOSAS patients. Their findings are at variance with those in the present study, perhaps due to their small sample size of only 70 patients. 
It was found that nasal obstruction was an independent contributor to OSAS with a weaker influence than hyoid bone position, male sex or obesity but stronger than age and mandibular characteristic. The weak relationship between daytime nasal resistance and AHI may be partly ascribable to a nocturnal change in nasal resistance. In addition, daytime physiological fluctuations in nasal resistance due to varying degrees of universal vascular congestions may have influenced the results. To reduce these fluctuations, posterior rhinomanometry, which shows less variation than anterior rhinomanometry [24] was used. In addition, to avoid the, vascular effects of posture, physical exercise, and exposure to extreme temperatures or pollutants, posterior rhinomanometry recording was started after a 30-min rest in the sitting position in a comfortable environment. Furthermore, to reduce both spontaneous and induced vascular changes, nasal decongestants were rou-tinely used when nasal resistance was $\geq 2.5 \mathrm{hPa} \cdot \mathrm{L} \cdot \mathrm{s}^{-1}$, or when unilateral nasal resistance for one nostril was $\geq 6 \mathrm{hPa} \cdot \mathrm{L} \cdot \mathrm{s}^{-1}$. Interestingly, AHI was less closely correlated to nasal resistance after nasal decongestion than to basal bilateral nasal resistance, although the relationship remained significant (table 2). This finding supports the hypothesis that both permanent physical nasal obstruction unresponsive to nasal decongestants, due for instance to nasal septum deviation, and functional nasal obstruction responsive to nasal decongestants, such as occurs during vasomotor rhinitis, contribute to sleepdisordered breathing. It is in agreement with clinical observations in OSAS $[8,10,19,25]$ showing that OSAS can be reversed by surgical correction of physical nasal obstruction or by medical and/or surgical correction of functional nasal obstruction.

To conclude, this study illustrates that daytime nasal obstruction, whatever the cause, is a risk factor for obstructive sleep apnoea syndrome. This factor is independent of other anthropometric factors. Its influence is less than that of obesity or cephalometric landmarks. However, because nasal obstruction can be treated, further studies are warranted to assess the clinical relevance of the findings.

Acknowledgements. The authors are grateful to E. Dahan for her skillful technical assistance.

\section{References}

1. Partinen M, Guilleminault C, Quera-Salva A, Jamieson A. Obstructive sleep apnea and cephalometric roentgenograms. The definition of anatomic upper airway abnormalities in the definition of abnormal breathing during sleep. Chest 1988; 93: 1199-1205.

2. Ferguson K, Ono T, Lowe A, Ryan F, Fleetham J. The relationship between obesity and craniofacial structure in obstructive sleep apnoea. Chest 1995; 108: 375-381.

3. Kushida C, Efrom B, Guilleminault C. A predictive morphometric model for obstructive sleep apnea syndrome. Ann Intern Med 1997; 127: 581-587.

4. Olsen KD, Kern EB, Westbrook PR. Sleep and breathing disturbances secondary to nasal obstruction. Otolaryngol Head Neck Surg 1981; 89: 804-810.

5. Zwillich C, Pickett C, Hanson F, Wiel J. Disturbed sleep and prolonged apnea during nasal obstruction in normal men. Am Rev Respir Dis 1981; 124: 158-160.

6. Lavie P, Gertner R, Zomer J, Podoshin L. Breathing disorders in sleep associated with "micro arousals" in patients with allergic rhinitis. Acta Otolaryngol (Stockh) 1981; 92: 529-533.

7. Lavie P, Fischel N, Zomer J, et al. The effects of partial and complete mechanical obstruction of the nasal passages on sleep structure and breathing in sleep. Acta Otolaryngol (Stockh) 1983; 95: 161-166.

8. McNicholas WT, Tarlo S, Cole P, Zamel N, Rutherford R, Griffin D. Obstructive apneas during sleep in patients with seasonal allergic rhinitis. Am Rev Respir Dis 1982; 126: 625-628.

9. Suratt PM, Turner BL, Wilhoit SC. Effect of intranasal obstruction on breathing during sleep. Chest 1986; 90 : 324-329.

10. Sériès F, St Pierre S, Carrier G. Surgical correction of nasal obstruction in the treatment of sleep apnea: importance of cephalometry in predicting outcome. Thorax 1993; 48: 360-363.

11. Miljeteig H, Hoffstein P, Cole P. The effects of unilateral and bilateral nasal obstruction on snoring and sleep apnea. Laryngoscope 1992; 102: 1150-1152.

12. Atkins M, Tashkar V, Clayton N, Stone P, Woodcock A. Nasal resistance in obstructive sleep apnea. Chest 1994; 105: 1133-1135.

13. Young T, Finn L, Kim H. Nasal obstruction as a risk factor for sleep disordered breathing. J Allergy Clin Immunol 1997; 99: S757-S762.

14. Rechtschaffen A, Kales A. A manual of standardized terminology, techniques and scoring system for sleep stages of human sleep. Bethesda, MD. National Institute of Neurological Disease and Blindness, 1968.

15. Quanjer P, Tammeling G, Cotes J, Pedersen O, Peslin R, Yernault J. Lung volumes and forced ventilatory flows. Report working party. Standardization of lung function tests. European community for steel and coal. Eur Respir $J$ 1993; 6, (Suppl. 16): 5-40.

16. Riley R, Guilleminault C, Herran J, Powell N. Cephalometric analyses and flow-volume loops in obstructive sleep apnea patients. Sleep 1983; 6(4): 303-311.

17. Coste A, Lofaso F, d'Ortho M, et al. Protruding the tongue improves posterior rhinomanometry in sleep apnea syndrome. Eur Resp J 1999; 14: 1278-1282.

18. Cole P. Rhinomanometry 1988: practice and trends. Laryngoscope 1989; 99: 311-315.

19. Dayal VS, Phillipson EA. Nasal surgery in the management of sleep apnea. Ann Otol Rhinol Laryngol 1985; 94: 550-554.

20. Blakeley B, Mahowald M. Nasal resistance and sleep apnea. Laryngoscope 1987; 97: 752-754.

21. Metes A, Ohki M, Cole P, Haight J, Hoffstein V. Snoring apnea and nasal resistance in men and women. $J$ Otolaryngol 1991; 20: 57-61.

22. Young T, Blustein J, Finn L, Palta M. Sleep-disordered breathing and motor vehicle accidents in a populationbased sample of employed adults. Sleep 1997; 20: 608613.

23. Desfonds P, Planès C, Furhman C, Foucher A, Raffestin B. Nasal resistance in snorers with or without sleep apnea: effect of posture and nasal ventilation with continuous positive airway pressure. Sleep 1998; 21: 622-629.

24. Dvoracek J, Hills A, Rossing R. Sequential anterior and posterior rhinomanometry. J Allergy Clin Immunol 1985; 76: 577-582.

25. Sériès F, St Pierre S, Carrier G. Effects of surgical correction of nasal obstruction in the treatment of obstructive sleep apnea. Am Rev Respir Dis 1992; 146: 12611265. 